\title{
Adaptive Structures, Robotics and Bio medics: A Perspective.
}

\author{
Concilio Antonio $^{1 *}$ and Carrino Luigi ${ }^{2}$ \\ ${ }^{1}$ Department of Adaptive Structures Division, the Italian Aerospace Research Centre, Italy \\ ${ }^{2}$ Department of Chemical, Materials and Production Engineering, University of Napoli Federico II, Italy
}

*Corresponding author: Concilio Antonio, Department of Adaptive Structures Division, the Italian Aerospace Research Centre, Capua CE, Italy.

To Cite This Article: Concilio Antonio, Adaptive Structures, Robotics and Bio medics: A Perspective. 2020 - 7(5). AJBSR.MS.ID.001187.

DOI: 10.34297/AJBSR.2020.07.001187.

Received: 眥 January 11, 2020 ; Published: 淎 February 27, 2020

Keywords: Robotics, Bio medics, Adaptive structures, Aerospace Engineering, HoloBuilder, Exoskeletons, Electromagnetic waves, Bioengineering, Biotechnology, Mechatronics

\section{Opinion}

Recently, some attention of the Aerospace Engineering field has moved towards smart or adaptive structures, and among them systems able to bear loads while deforming their shape or changing their geometrical configuration (morphing). Many issues must still be faced and completely overcome in order to practically implement such a kind of architectures, as illustrated in some representative textbooks [1-3]. The main of them, however, stands just in the foreword: creating structures that shall withstand external force with minimal deformation while having the capability to change their outline. A contradictory characteristic that is sometimes referred to as "the paradox of smart (or adaptive) structures". Indeed, this kind of aspect is not brand new. General aircraft have special devices for manoeuvre (as flaps and slats) or cruise control (as ailerons), which make possible to "change the wing geometry" so to face different needs at different speeds and environmental conditions (ascent, descent, turn and so on).

Either, some movable devices are already implemented to alleviate gust effects. What is new in the proposed layouts, among many other aspects that would require more detailed attention, is the perfect integration of active components (actuator and sensor systems) and adaptive skeleton (deformable structure), sometimes shrouded by a highly deformable skin. The result is a wing that can change its shape without any evidence of the internal apparatus that allows this capacity. At the time being, the most advanced studies confined the movement to essential features. For instance, some devices proposed three degrees of freedom schemes along the chord, usually composed with increasing complexity along the span to enable articulated camber curvature, almost resembling a wide and complex finger or even almost a continuous hand (kinematic systems). It is possible to find in literature more complex elaborations of that concept, enabling translation and further combined movements, but the basic layout remains.

Something different can be found in the compliant systems, where embedded kinematics aims at deforming a continuous elastic structure, namely generating a larger number of degrees of freedom. Even in that case however, the implemented architecture produces limited additional mobility. Within these boundaries, results are yet incredibly interesting. Projects like SARISTU in Europe [2], or Adaptive Compliant Trailing Edge in USA [4], proposed full-size wing integrated with multiple actuation systems and distributed sensor networks. In detail, SARISTU presented a $5.5 \mathrm{~m}$ span wing equipped with an adaptive leading edge (the fore part of the wing), an adaptive trailing edge (the aft part) and a winglet (the wing tip), capable to give the basic structure incredible shape variations. It was tested in Wind Tunnel up to M 0.3 (around $300 \mathrm{~km} / \mathrm{h}$ at sea level), after having been sized for M 0.75 (a common velocity for an airline airplane). In the Adaptive Compliant Trailing Edge project, a flying prototype of an adaptive flap was fully integrated in the wing body, 
attaining something like $45 \mathrm{deg}$ deflection without discontinuity in the camber curvature (i.e., continuous deformation).

The aircraft took off and landed with this novel system, in principle aimed at replacing typical movables of any air vehicle. Robotics may be seen somehow related to adaptive structures. In that case, the problem is approached from "another perspective". Rigorously, a robot is any machine that serves heavy work, replacing the need of human strength. A washing machine, a simple pallet truck are examples of robots. In the collective imaginary however, the word robot has been more and more associated to something that tries to replicate behavior and operation of a human, while the other systems are indicated with the generic term of machines, more brutally and perhaps efficiently. Thus, when a robot is introduced, it is often a mechanical system that imitates the characteristics of a man or a woman, to some extent. More in general, a robot is also associated to something that replicates a living creature as a $\mathrm{dog}$, a cat or even an insect. Biomimetic robots have completely assimilated the meaning of the word robot, almost for antonomasia.

The step forwards that have been moved by this technology in the recent years are impressive. There do exist robot able to play soccer [5] to shoot with extreme precision [6] to bring delicate substances from a place to another [7] and even to operate autonomously, almost or completely. That latter aspect is however part other subjects and is herein left apart. What is the focus of the research on robots, in the sense now described, is for instance associated to the need of moving in perfect equilibrium, avoiding falls or even uncertain steps, or to the capability of handling things with extreme care, without hurting or damaging them, and so on. In other words, the focus of the robot as a mechanical system is "to be precise" in the most extensive sense of that statement. Generally, it is possible to state that there is no special focus on the force that shall be exerted to resist external loads or applied to an external object. Sometimes, the study effort is spent to control it at the minimum as in the case of manipulating eggs or delicate surgery tools [8].

The robot structure itself is not thought as something that can be deformable: it can be described as a set of rigid parts (multibody system). If increasing weight had not a direct impact on the actuators power, and then on their size, it would be also correct to assert that weight is not an issue for that kind of machines. Among many outstanding projects that can be found in literature, the following are good examples of what stated until now. Supported by the European Research Council (ERC), the SOFTHANDS team did succeed in creating a hand robot that matched ability to move and to apply different levels of strength [9]. HoloBuilder, a software house specialized in products for supporting civil constructor operations, and Boston Dynamics, a robotics firm, released a doglike robot (SPOT) to catch regular comprehensive overviews of ongoing activities, and monitor and report real-time variations on the scheduled path [10]. Potentialities of that same robot have been also experimented by the Massachusetts State Police.

Standing that background and hazarding a futuristic vision along the route tracked by many movies on the matter, it is easy to imagine how the developments of adaptive structures and robotics could meet at some point. Realization of robots able to change their shape as a function of their mission, strong enough to resist significant loads while being able to handle things with extreme precision, sufficiently accurate to substitute human hands operation in microscopic surgery, is something that is perfectly imaginable at this point of the research activities and their next evolutions. There is no need of having some capability or sensitiveness for looking forward to the times ahead. Maybe romantic perspectives, presented by movies like Transformers [11] or Terminator [12] will never come to reality, but the essence of the prospected mental picture is exactly that. Making a further step ahead or aside, it can be also envisaged how robotic parts could be integrated into human body to help people with disabilities in overcoming their difficulties or handicaps, even if partially.

Exoskeletons are first examples of this further possibility that brilliantly avoid facing problems as the direct incorporation of mechanical systems on a person (cyborg). Some of those are classical mechanic issues, as for instance, the need of ensuring a perfect fitting with the bones, while controlling tensions and strains transmitted to the coupling interface. Others regard extremely complex biomedical aspects as the connection to sensitive terminals and information pathways (nerves) to the machine and vice-versa, in the way shown in Star Wars Episode V [13]. If someone should express some concerns about the actual possibility that cyborgs will be present in the far future, it could be answered that many of us are perhaps already those ones $[14,15]$. Today, people are so associated with their connection means (PC, tablet, smartphones and so on) that these latter may be already considered as parts of their body. And if the issue should be those devices are not physically linked, the obvious answer, which in turn is a rhetoric question, would be "for how long?".

Wearing a chip under the skin is possible (our dogs already have it) and implementing voice commands is a diffused technology. Studies are ongoing for catching the brainwaves and using them to drive easy tasks of certain apparatuses [16]. A kind of mind transmission via electromagnetic waves (enhanced phone calls) is not that far. It maybe these latter items move this speech too away from the original intentions, having started dealing with cybernetics, either. Coming back to the perspectives, robotics, mechatronics and adaptive structures science seem to be converging in the short-medium term, with some expected and many unexpected consequences on Bio medics, bioengineering and biotechnology. 


\section{References}

1. Concilio A, Dimino I, Lecce L, Pecora R (2017) Morphing Wing Technologies: Large Commercial Aircraft and Civil Helicopters. Elsevier Science pp.978.

2. Woelcken PC, Papadopoulos M (2015) Smart Intelligent Aircraft Structures (SARISTU): Proceedings of the Final Project Conference. Springer International Publishing, USA.

3. Valasek J (2012) Morphing Aerospace Vehicles and Structures. Aerospace Series, Wiley, USA

4. Cumming SB, Smith MS, Ali AN, Bui TT, Ellsworth JC, et al. (2016) Aerodynamic Flight-Test Results for the Adaptive Compliant Trailing Edge. AIAA Atmospheric Flight Mechanics Conference.

5. Dan X, Junhao X, Huimin L, Zhiwen Z, Qinghua J, et al. (2016) The design of an intelligent soccer-playing robot. Industrial Robot: An International Journal 43: 91-102.

6. Lindner C (2019) Skip the New Terminator and Watch This Unnerving Robo-Apocalypse Instead. Popular Mechanics, USA.

7. Ashish S, Amanpreet S (2016) Kinematic Modeling of Robotic Manipulators. Proceedings of the National Academy of Sciences 87(3): 303-319.

8. Su H, Yang C, Ferrigno G, Momi ED (2019) Improved Human-Robot Collaborative Control of Redundant Robot for Teleoperated Minimally Invasive Surgery. IEEE Robotics and Automation 4(2): 1447-1453.

9. Piazza C, Catalano MG, Godfrey SB, Rossi M, Grioli G, et al. (2017) The Soft Hand Pro-H: A Hybrid Body-Controlled, Electrically Powered Hand Prosthesis for Daily Living and Working. IEEE Robotics \& Automation Magazine 24(4): 87-101.
10.Zeiba D (2019) Roaming robot dogs could streamline jobsite documentation. The Architect Newspaper.

11. The Transformers: The Movie, Director: Nelson Shin, Production companyl: | Sunbow Productions, Marvel Productions, Toei Animation, Produced by:: Jjoe Bacal, Tom Griffith, Edited by: [David Hankins, Music by|: Vince Di Cola, 1986.

12. Terminator 2, Director: James Cameron, Production company: ‘ Carolco Pictures, Pacific Western Productions, Lightstorm Entertainment, Le Studio Canal+ S.A., Produced by: Mark Goldblatt, Richard A. Harris, Music by|: Brad Fiedel.

13. Star Wars, Episode V, Director: Irvin Kershner, Production company: Lucasfilm Ltd., Produced by: "Gary Kurtz, Edited by: "Paul Hirsch, Screenplay by: [Leigh Brackett; [Lawrence Kasdan, Music by: John Williams.

14. Pohl R (2019) Donna Haraway's a Cyborg Manifesto. The Macat Library. London, UK.

15. Haraway DJ, Wolfe C (2016) Manifestly Haraway. University of Minnesota Press, Minnesota, USA.

16. AL Quraishi MS, Elamvazuthi I, Daud SA, Parasuraman S, Borboni A (2018) EEG-Based Control for Upper and Lower Limb Exoskeletons and Prostheses: A Systematic Review. Sensors 18(10): 27. 